\title{
Evaluation of a Flow-Through Depuration System to Eliminate the Human Pathogen Vibrio Vulnificus from Oysters
}

\author{
Matthew Lewis, Scott Rikard and Covadonga R. Arias* \\ Department of Fisheries and Allied Aquacultures, 203 Swingle Hall. Auburn University. Auburn, AL 36849, USA
}

\begin{abstract}
The efficacy of a flow-through depuration system in eliminating the human pathogen Vibrio vulnificus from eastern oysters (Crassostrea virginica) collected from the North Gulf of Mexico coast was evaluated in this study. Depuration experiments were conducted with artificially inoculated oysters using laboratory-grown strains of $V$. vulnificus as well as with naturally contaminated oysters. Determination of $V$. vulnificus numbers in oyster tissues was conducted at $0,1,2$, 3 and 6 days of depuration. Results showed that the depuration of $V$ vulnificus is possible using a flow-through system. Numbers of $V$. vulnificus in laboratory-inoculated oysters were reduced from $>100,000$ Most Probable Number (MPN)/g of oyster tissue to $23 \mathrm{MPN} / \mathrm{g}$ after six days of depuration. As expected depuration results of naturally contaminated oysters were more variable. Depuration at low temperature $\left(15^{\circ} \mathrm{C}\right)$ had very little success in reducing the numbers of $V$. vulnificus in oyster tissues. On the contrary, when flow rate was increased from $11 \mathrm{~L} / \mathrm{m}$ to $68 \mathrm{~L} / \mathrm{m}$, numbers of $V$. vulnificus in oysters were reduced from a starting concentration of $110,000 \mathrm{MPN} / \mathrm{g}$ to $3 \mathrm{MPN} / \mathrm{g}$ in six days. Nevertheless, a high-flow rate was not enough to eliminate $V$. vulnificus from oysters consistently. Vibrio vulnificus was effectively eliminated from oysters only when incoming water salinity was higher than 30 parts per thousand (ppt). Depuration did not select for pathogenic $V$. vulnificus strains. Pre- and post depuration $V$. vulnificus isolates contained similar proportions of the proposed more virulent type.
\end{abstract}

\section{Introduction}

Vibrio vulnificus is an opportunistic human pathogen that is an indigenous member of estuarine and marine habitats. Numbers of $V$. vulnificus in seawater, sediments, marine invertebrates and fish are not related to pollution or other forms of contamination [1]. Though distributed worldwide, $V$. vulnificus is commonly found in the United States (US) along the Gulf of Mexico coast where temperatures are subtropical and salinities are relatively low allowing for its optimum survival [2,3]. The eastern oyster (Crassostrea virginica) also thrives in this geographic region supporting an economically important commercial industry. Oysters are filter feeders that tend to concentrate microbes present in surrounding waters some of which can cause severe illness in humans $[4,5]$. Since most oysters are eaten alive, raw or poorly cooked, they can act as vectors for pathogenic microbes including $V$. vulnificus. This human pathogen can cause primary septicemia in susceptible individuals with the highest reported mortality rate $(>50 \%)$ of any food-borne pathogen [6,7].

In 2008, the US eastern oyster industry landings were valued at $\$ 82$ million with the Gulf of Mexico accounting for over $89 \%$ of the total harvest [8]. However, the mandatory warning labels required on Gulf coast oysters due to the high prevalence of $V$. vulnificus in this region has resulted in an overall decline in consumer demand and a reduction of summer price by $50 \%[9,10]$. There are several methods approved by the Federal Drug Administration (FDA) for post-harvest processing of oysters that eliminate $V$. vulnificus: high hydrostatic pressure (HHP), heat/cool pasteurization (HCP), individually quick frozen (IQF), and irradiation. However, all of these methods change the organoleptic properties of oysters and consumers tend to not appreciate them as much $[11,12]$.

Depuration is defined as the transfer of shellfish containing bacteria to a controlled, clean aquatic environment that permits them to open and function in an optimum physiological mode that favors the elimination of bacteria to non-detectable levels favorable for human consumption without requiring further processing $[13,14]$. The efficacy of this post-harvest process in reducing $V$. vulnificus in oysters inoculated with laboratory grown strains has been proved successful [15-17]. However, there has been little success with depuration of naturally present $V$. vulnificus strains in oysters using closed, re-circulating systems probably due to recontamination of the oysters [15-17]. The present study was conducted to i) determine the efficacy of a flow-through depuration system to eliminate $V$. vulnificus from eastern oysters and 2) assess if the selecting pressured imposed by depuration selects for certain strains of $V$. vulnificus that may harbor a higher pathogenic potential for humans [18].

\section{Materials and Methods}

\section{Bacterial strains and cultures preparation}

Vibrio vulnificus reference strain $\mathrm{Vv} 3$, originally isolated from Gulf oysters harvested in Alabama, USA, was used in this study to artificially inoculate oysters [19]. Cells were cultured in $50 \mathrm{~mL}$ conical vials containing marine broth (MB) (Difco, Detroit, MI, USA) at $35^{\circ} \mathrm{C}$ with shaking for $12 \mathrm{~h}$.

During depuration experiments, putative $V$. vulnificus isolates were collected from modified cellobiose polymyxin colistin agar $(\mathrm{mCPC})$ before and after depuration and maintained in $0.3 \%$ marine agar (MA) (Difco, Detroit, MI, USA) at room temperature for further characterization.

\section{Oyster stock}

Two year-old oysters were obtained from Auburn University

*Corresponding author: Covadonga R. Arias, 203 Swingle Hall, Auburn University, Auburn AL 36849, USA, Email: ariascr@auburn.edu

Received October 18, 2010; Accepted November 24, 2010; Published Novembe 25, 2010

Citation: Lewis M, Rikard S, Arias CR (2010) Evaluation of a Flow-Through Depuration System to Eliminate the Human Pathogen Vibrio Vulnificus from Oysters. J Aquac Res Development 1:103. doi:10.4172/2155-9546.1000103

Copyright: ( 2010 Lewis M, et al. This is an open-access article distributed unde the terms of the Creative Commons Attribution License, which permits unrestricted use, distribution, and reproduction in any medium, provided the original author and source are credited. 
Shellfish Lab (AUSL) on Dauphin Island, AL. The oysters were grown in $16 \mathrm{~mm}$ mesh bags on an adjustable long line system (BST Oyster Supply, Cowel, South Australia) in an intertidal area below a boat dock about $46 \mathrm{~cm}$ off the bottom at the following coordinates: $30^{\circ}$ 15 " 04.68" N, $88^{\circ} 04$ " 47.28" W.

\section{Oyster depuration}

For each depuration experiment, sixty oysters were harvested and cleaned of any fouling organisms and transferred to the depuration system. Oysters were placed on mesh trays suspended $13 \mathrm{~cm}$ off the bottom in a $522 \mathrm{~L}$ raceway tank with a water volume of around 300 L. Seawater was piped in from the Gulf of Mexico with a $213 \mathrm{~m}$ PVC pipeline extending $107 \mathrm{~m}$ offshore. Incoming seawater was filtered through a $200 \mu \mathrm{m}$ bag filter (Aquatic Ecosystems, Inc., Apopka, FL, USA) then treated with a $110 \mathrm{~W}$ commercial UV sterilizer (Tropical Marine Centre, Ltd., Chorleywood, UK) (only in the test tank). Oysters were depurated using a water flow-through system with flow rate maintained at $11 \mathrm{~L} / \mathrm{m}$ (unless specified otherwise) for 6 days at the AUSL. The approximate water replacement time of the system was 30 min. Oysters were fed once a day with marine microalgae concentrate (Shellfish Diet 1800, Reed Mariculture, Campbell, CA, USA), requiring cessation of water flow for $1 \mathrm{~h}$ per feeding. The tanks were drained daily and cleaned of feces and pseudofeces with tapwater. Filter bags were also cleaned daily by thoroughly rinsing with tap water. Salinity and temperature were measured twice a day with a YSI model 85 probe (YSI Inc., Yellow Springs, OH, USA). Mortality was checked every morning before cleaning. The control tank was a replica of the test tank without the bag filter and UV filter (incoming seawater in the control tank was not treated at all). Populations of $V$. vulnificus in oysters were analyzed at $0,1,2,3$ and 6 days during the depuration process.

Depuration of artificially inoculated oysters: Oysters were collected as described above during the month of February (Experiments 1 and 2) when numbers of $V$. vulnificus are typically non-detectable in shellfish. Before oysters were placed in depuration tanks, a subsample was taken for bacteriological analysis (see below). Oysters were found negative for the presence of native $V$. vulnificus strains. Artificially inoculation was carried out according to Limthammahisorn et al., [19]. Briefly, 150 oysters were placed into $38 \mathrm{~L}$ aquaria with 27 $\mathrm{L}$ of autoclaved seawater at $25^{\circ} \mathrm{C}$ and were allowed to acclimate for 24 h. Vibrio vulnificus Vv3 strain was incubated overnight at $35^{\circ} \mathrm{C}$ in marine broth. Cultures were spectrophotometrically quantified and a final concentration of $3.7 \times 10^{5}$ Colony Forming Units (CFU)/ $\mathrm{ml}$ of $\mathrm{V}$. vulnificus was achieved in each tank (approximately $10^{10} \mathrm{~V}$. vulnificus cells were added to each tank). Oysters were artificially contaminated with $V$. vulnificus by self-inoculation filtration at $25^{\circ} \mathrm{C}$.
After inoculation, oysters were placed into depuration tanks and depurated as described above.

Depuration of naturally contaminated oysters: In Experiments 3 to 7 , oysters were collected when water temperature was above $25^{\circ} \mathrm{C}$ and therefore they were presumed to contain $V$. vulnificus. Oysters were collected as described above and tested for the presence of $V$. vulnificus before starting depuration. Initial levels of $V$. vulnificus varied but were above $10^{3} \mathrm{MPN} / \mathrm{g}$ in all cases. Experiment 3 used the same flow-rate and as Experiments 1 and 2 and established the baseline for depurating naturally contaminated oysters. In Experiment 4 , oysters were depurated under cold temperature by using a chiller unit (Delta Star chiller, AquaLogic Inc., San Diego, CA, USA) that was attached to the test tank to maintain incoming seawater at $15^{\circ} \mathrm{C}$ Water temperature in the control tank was not modified and remained at $25.0 \pm 2.1^{\circ} \mathrm{C}$ for the duration of the experiment. In experiments 5 , 6 and 7 the depuration system was tested under different flow rates. In Experiment 5, flow rate was increased up to $48 \mathrm{~L} / \mathrm{min}$ (from the 11 $\mathrm{L} / \mathrm{min}$ flow rate used in previous experiments) while flow rate was increased to a maximum of $68 \mathrm{~L} / \mathrm{min}$ in Experiments 6 and 7.

\section{Bacteriological analysis}

Numbers of $V$. vulnificus in oysters were determined at day 0 (before oysters were placed in the tanks) and at 1,2, 3 and 6 days of during the depuration process. Twelve oysters were analyzed each time according to 3-tube Most Probable Number (MPN) method described in the U.S. Food and Drug Administration's Bacteriological Analytical Manual (BAM) [20] using mCPC. Numbers of V. vulnificus are given as MPN/g of oyster tissue (or a $\log \mathrm{MPN} / \mathrm{g}$ ).

\section{Characterization of $V$. vulnificus isolates obtained before and after depuration}

In order to determine if depuration selects for specific $V$. vulnificus types, isolates were recovered pre- and post-depuration during Experiment 6. A total of 97 putative isolates (41 pre-depuration and 56 at 6 days post-depuration) were recovered on mCPC. DNA was extracted according to Pitcher et al. [21] after isolates were plated onto MA plates and incubated at $37^{\circ} \mathrm{C}$ for $16 \mathrm{~h}$. DNA was resuspended in $200 \mu \mathrm{L}$ of deionized water $\left(\mathrm{dH}_{2} \mathrm{O}\right)$ and stored at $-20^{\circ} \mathrm{C}$. DNA was quantified using the Nanodrop ${ }^{\circledR}$ ND-1000 Spectrophotometer (Thermo Scientific, Wilmington, DE, USA) and diluted to $20 \mathrm{ng} / \mu \mathrm{L}$. Confirmation of V. vulnificus presumptive isolates was carried out by specific PCR amplification of the vvh gene as per Panicker and Bej [22]. Only isolates confirmed as V. vulnificus by specific PCR were used for genotyping analysis.

Restriction Fragment Length Polymorphism (RFLP) of the $16 S$ rDNA. Strains were ascribed to $16 \mathrm{~S}$ type A or B according to

\begin{tabular}{|c|c|c|c|c|c|c|}
\hline \multirow[b]{2}{*}{ Experiment } & \multirow[b]{2}{*}{ Date } & \multicolumn{3}{|c|}{ Vibrio vulnificus counts (MPN/g) ${ }^{a}$} & \multirow[b]{2}{*}{ Temperature $\left({ }^{\circ} \mathrm{C}\right)^{\mathrm{b}}$} & \multirow[b]{2}{*}{ Salinity $(p p t)^{\circ}$} \\
\hline & & Pre-depuration & Post-depuration Control tank & Post-depuration Test tank & & \\
\hline 1- Inoculated oysters & 02/19/2009 & $>1.1 \times 10^{5}$ & 75 & 43 & $18.0 \pm 1.7$ & $25.0 \pm 2.8$ \\
\hline 2- Inoculated oysters & 02/26/2009 & $>1.1 \times 10^{5}$ & 23 & 20 & $15.0 \pm 1.1$ & $27.0 \pm 1.7$ \\
\hline 3- Standard & 06/19/2009 & $1.4 \times 10^{3}$ & $9.3 \times 10^{2}$ & $2.4 \times 10^{3}$ & $28.3 \pm 1.7$ & $24.3 \pm 2.3$ \\
\hline 4- Low Temp. $15^{\circ} \mathrm{C}$ & 08/08/2009 & $2.9 \times 10^{4}$ & $7.5 \times 10^{3}$ & $9.3 \times 10^{3}$ & $25.0 \pm 2.1$ & $26.5 \pm 3.2$ \\
\hline 5- Flow rate $46 \mathrm{~L} / \mathrm{min}$ & 09/01/2009 & $>1.1 \times 10^{5}$ & $2.1 \times 10^{4}$ & $2.9 \times 10^{4}$ & $28.5 \pm 0.6$ & $26.0 \pm 3.4$ \\
\hline 6- Flow rate $68 \mathrm{~L} / \mathrm{min}$ & 09/14/2009 & $1.1 \times 10^{5}$ & 3 & 3 & $27.5 \pm 1.7$ & $32.2 \pm 1.2$ \\
\hline 7- Flow rate $68 \mathrm{~L} / \mathrm{min}$ & 10/12/2009 & $4.6 \times 10^{4}$ & $1.1 \times 10^{5}$ & $>1.1 \times 10^{5}$ & $25.6 \pm 3.1$ & $9.0 \pm 2.4$ \\
\hline
\end{tabular}

${ }^{a}$ Vibrio vulnificus counts were determined according to Most Probable Number (MPN) method described in the U.S. Food and Drug Administration's Bacteriological Analytical Manual (BAM) [5]

${ }^{b}$ Average seawater temperature recorded in both tanks throughout the depuration process

${ }^{\mathrm{c}}$ Average seawater salinity recorded in both tanks throughout the depuration process

Table 1: Summary of depuration trials. 


\begin{tabular}{|l|l|l|l|}
\hline 16S-RFLP type & Pre-depuration & Post-depuration & Total \\
\hline Type A & 26 & 25 & 51 \\
\hline Type B & 15 & 31 & 46 \\
\hline
\end{tabular}

Table 2: Number of Vibrio vulnificus isolates that belong to 16S-RFLP type A and B.

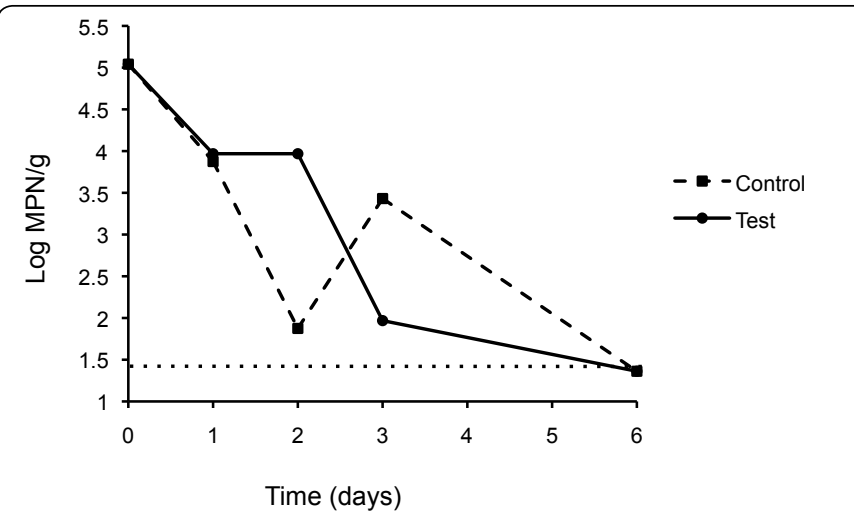

Figure 1: Reduction of Vibrio vulnificus in artificially-inoculated oysters (Experiment 1) subjected to flow-through depuration over a 6-day period as determined by Most Probable Number (MPN) analysis. Graph represents log of MPN/gram of oyster meat. Seawater in test tank was UV filtered. Dotted line represents the $30 \mathrm{MPN} / \mathrm{g}$ threshold of reduction required by the Federal Drug Administration (FDA) for validation of the system.

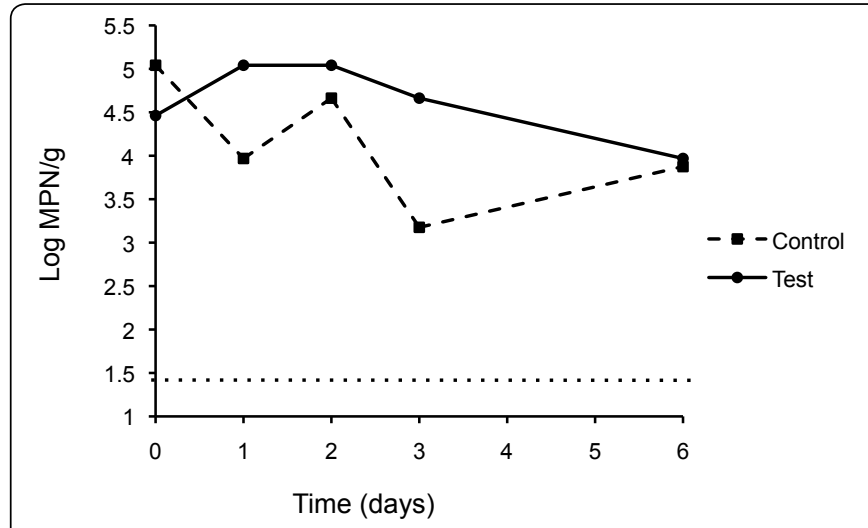

Figure 2: Persistence of Vibrio vulnificus in naturally contaminated oyster tissue (Experiment 4) subjected to flow-through depuration at $15^{\circ} \mathrm{C}$ (test tank) over a 6-day period as determined by Most Probable Number (MPN) analysis. Graph represents log of MPN/gram of oyster meat. Dotted line represents the $30 \mathrm{MPN} / \mathrm{g}$ threshold of reduction required by the Federal Drug Administration (FDA) for validation of the system.

Nilsson et al. [18]. Amplification of $16 \mathrm{~S}$ rDNA was carried out with primers UFUL (5'- GCCTAACACATGCAAGTCGA-3') and UFUR (5'CGTATTACCGCGGCTGCTGG-3'). Following digestion with HaelII, restriction fragments were electrophoresed in a 3\% TAE Agarose- 1000 (Invitrogen, Carlsbad, CA, USA) gel for $90 \mathrm{~min}$ at $80 \mathrm{~V}$, stained with ethidium bromide, and photographed under UV light.

Amplified Fragment Length Polymorphism (AFLP): AFLP fingerprintings were determined as previously described by Arias et al. (1997) with the following modifications. PCR amplifications were performed using the MJ Research PTC-200 Thermocycler with the following cycle profile: cycle $1,60 \mathrm{~s}$ at $94^{\circ} \mathrm{C}, 30 \mathrm{~s} 65^{\circ} \mathrm{C}$, and $60 \mathrm{~s}$ at $72^{\circ} \mathrm{C}$; cycles 2 to $12,30 \mathrm{~s}$ at $94^{\circ} \mathrm{C}, 30 \mathrm{~s}$ at annealing temperatures $0.7^{\circ} \mathrm{C}$ lower than that used for each previous cycle, starting at $64.3^{\circ} \mathrm{C}$, and $60 \mathrm{~s}$ at $72^{\circ} \mathrm{C}$; cycles 13 to $24,30 \mathrm{~s}$ at $94^{\circ} \mathrm{C}, 30 \mathrm{~s}$ at $56^{\circ} \mathrm{C}$ and 60 $\mathrm{s}$ at $72^{\circ} \mathrm{C}$. After completion of the cycling program, $5 \mu \mathrm{L}$ of $\mathrm{AFLP} \circledast$ Blue Stop Solution (LI-COR) was added to the reaction mixtures.
Prior to gel loading, the samples were heated for $5 \mathrm{~m}$ at $94^{\circ} \mathrm{C}$ then rapidly cooled on ice to prevent reannealing. The PCR products were electrophoresed on the NEN Global Edition IR2 DNA Analyzer (LICOR) following manufacturer's instructions.

\section{Data analysis}

A depuration experiment was considered successful if numbers of $V$. vulnificus were below the FDA threshold of $<30 \mathrm{MPN} / \mathrm{g}$ of oysters. Correlation between salinity and $V$. vulnificus numbers at the end of the depuration trials was calculated using the Pearson product moment correlation coefficient. Ascription of $V$. vulnificus strains to ribosomal types $16 \mathrm{~S}$-A and $16 \mathrm{~S}$-B was done according to the restriction fragments size [18]. AFLP images were processed with BioNumerics v 5.0 (Applied Maths Inc., Austin, TX, USA). Following conversion, normalization, and background subtraction with mathematical algorithms, levels of similarity between fingerprints were calculated with the Pearson product-moment correlation coefficient. Cluster analysis was performed with the unweighted pair-group method using average linkages (UPGMA).

\section{Results}

Table 1 summarizes the results obtained from depuration tests through the year 2009. As expected, average temperature and salinity, as well as initial V. vulnificus numbers, changed seasonally.

Depuration of artificially contaminated oysters: Oysters were successfully inoculated with $V$. vulnificus by filtering water. Before depuration numbers of $V$. vulnificus in inoculated oyster tissues were $>10^{5} \mathrm{MPN} / \mathrm{g}$ of tissue. Figure 1 shows the decline in $\mathrm{V}$. vulnificus counts during depuration from Experiment 1. After six days in the depuration tanks, $V$. vulnificus numbers in oysters were reduced by more than 4 orders of magnitude. Similar results were obtained when the experiment was repeated (Experiment 2, see Table 1). Interestingly, the use of a UV filter seemed to have little effect in decontaminating oysters. After 6 days of depuration, oysters in both test and control tanks contained similar numbers of $V$. vulnificus.

Depuration of naturally contaminated oysters: In Experiment 3, oysters harvested from the wild were subjected to depuration using a flow rate of $11 \mathrm{~L} / \mathrm{min}$, as in Experiments 1 and 2. Initial $V$. vulnificus counts were at $1.4 \times 10^{3} \mathrm{MPN} / \mathrm{g}$ and did not significantly changed in oysters during the depuration trial (Table 1). In Experiment 4, water

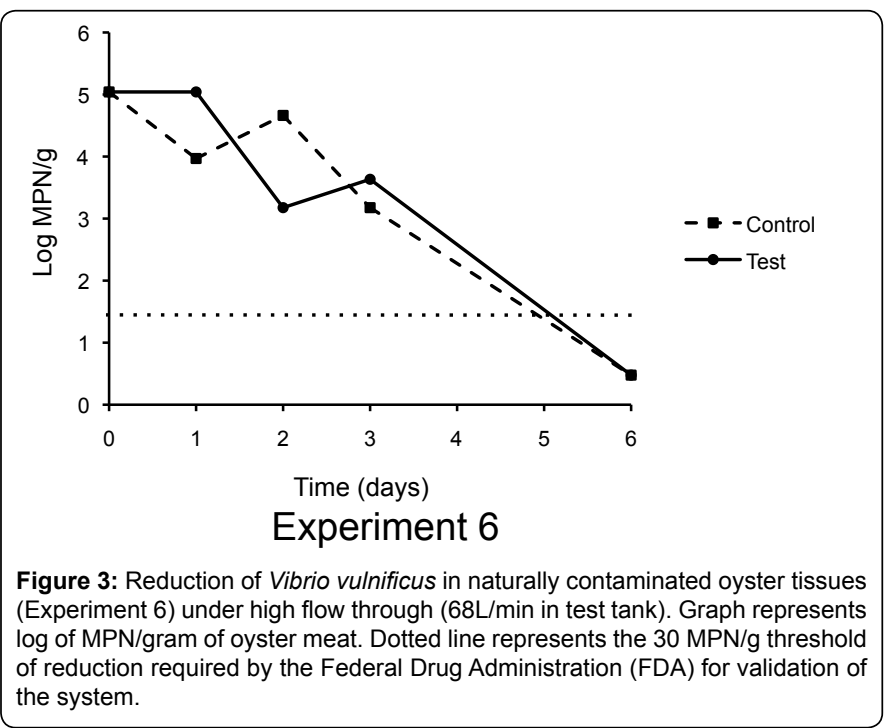


Citation: Lewis M, Rikard S, Arias CR (2010) Evaluation of a Flow-Through Depuration System to Eliminate the Human Pathogen Vibrio Vulnificus from Oysters. J Aquac Res Development 1:103. doi:10.4172/2155-9546.1000103

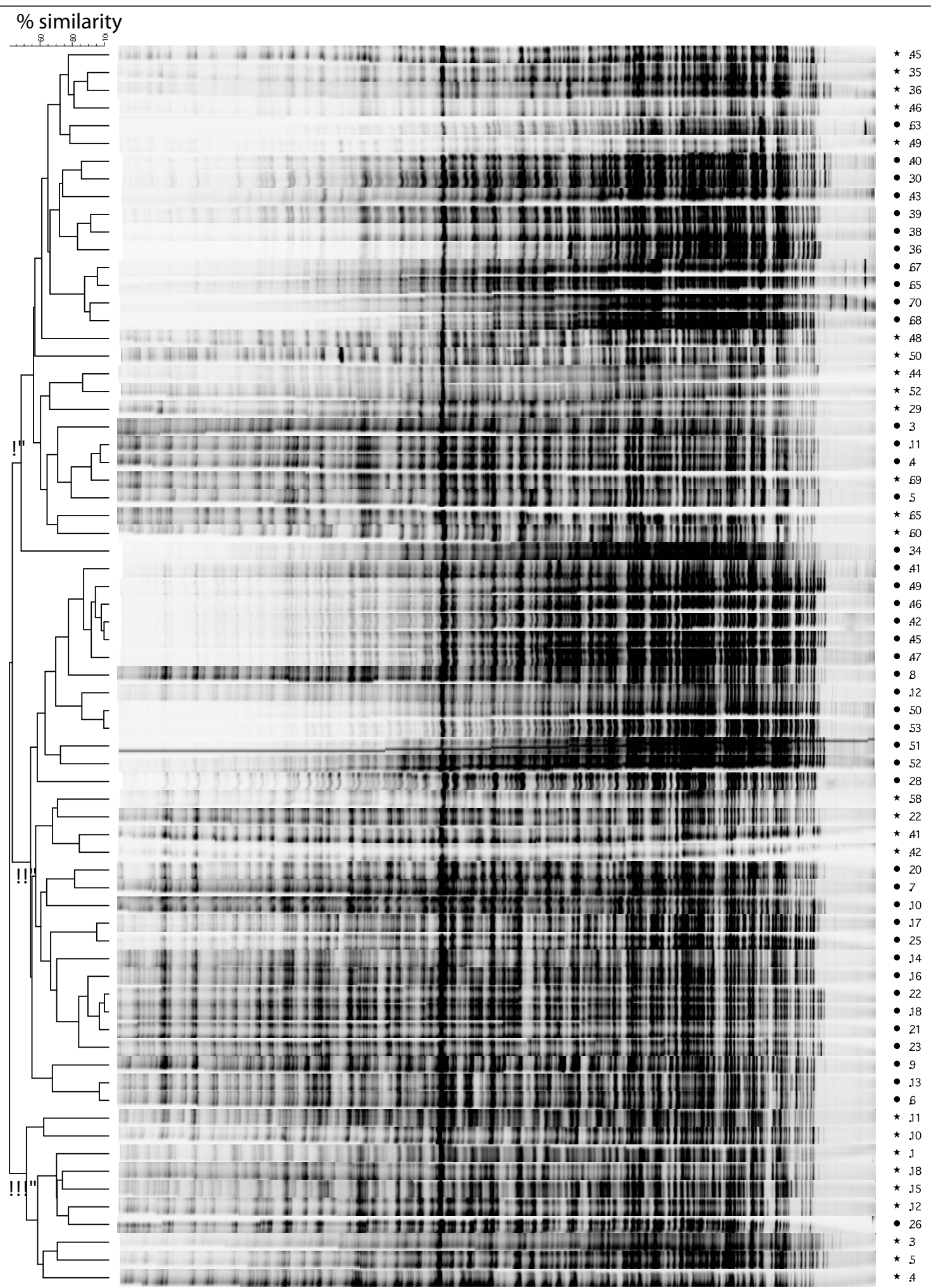

Figure 4: AFLP patterns of Vibrio vulnificus isolates recovered from oysters. The dendogram was derived by UPGMA cluster analysis of the AFLP profiles of $70 \mathrm{~V}$. vulnificus isolates. The tracks show the processed band patterns after conversion, normalization, and background subtraction. Levels of linkage are expressed as the Pearson product-moment similarity coefficient. Major clusters are noted with roman numerals. Star symbols represent pre-depuration isolates while solid circles represent post-depuration isolates.

temperature was artificially modified by using a chilling unit. We found no major reduction in $V$. vulnificus numbers when oysters were depurated at $15^{\circ} \mathrm{C}$ (Figure 2). An alternative option for improving depuration efficiency was increasing flow rate. We hypothesized that an increase in flow rate could boost the ventilation rate of the oysters and therefore result in higher reductions of $V$. vulnificus from 


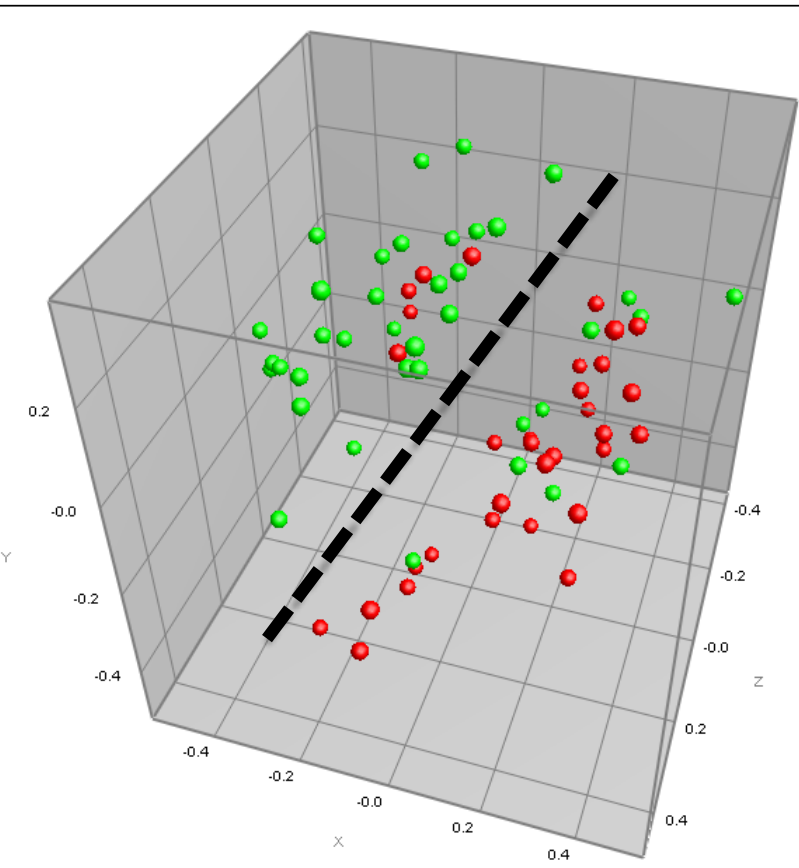

Figure 5: Multidimensional scaling (MDS) plot showing the relatedness of Vibrio vulnificus isolates based on AFLP data. Distance between entries represents dissimilarities obtained from the similarity matrix. Dotted line shows the division between the two dominant groups, one containing primarily $16 \mathrm{~S}$ type $\mathrm{A}$ isolates (red) while the other contains mainly $16 \mathrm{~S}$ type B (green).

oyster tissues. The first arbitrary increase from the standard $11 \mathrm{~L} /$ min was to $46 \mathrm{~L} / \mathrm{min}$. The results from this test are shown in Table 1 , Experiment 5 . At day 0 more than $1 \times 10^{5} \mathrm{MPN} / \mathrm{g}$ of $\mathrm{V}$. vulnificus were present in oyster tissues. By day 6 , the numbers had decreased down to $2.9 \times 10^{4} \mathrm{MPN} / \mathrm{g}$. The results of this experiment indicated that a higher flow rate might hold promise for the elimination of $V$. vulnificus from oysters in a flow-through depuration system. Figure 3 shows the results obtained from Experiment 6, in where flow rate was increased to $68 \mathrm{~L} / \mathrm{min}$. During this experiment $V$. vulnificus numbers in oyster tissues went from $1.1 \times 10^{5} \mathrm{MPN} / \mathrm{g}$ at day 0 down to $3 \mathrm{MPN} / \mathrm{g}$ by day 6 . This final concentration is below the FDA required $<30$ $\mathrm{MPN} / \mathrm{g}$ for validation of a new system for post-harvest processing of oysters. Experiment 7 used the same flow rate as Experiment 6 but was performed a month later and yielded very different results. Vibrio vulnificus numbers in oyster were $4.6 \times 10^{3} \mathrm{MPN} / \mathrm{g}$ at day 0 and actually increased to over $1 \times 10^{5} \mathrm{MPN} / \mathrm{g}$ at day 6 . It is noteworthy that the salinity of the incoming seawater was very different between the two experiments. In Experiment 6, salinity remained above $30 \mathrm{ppt}$ during depuration while in Experiment 7 average salinity was below $10 \mathrm{ppt}$. When final $V$. vulnificus counts were plotted against salinity, a significant correlation was observed $(r=0.79)$.

Characterization of Vibrio vulnificus isolates recovered pre- and post-depuration: To determine if depuration selects for a certain strain of $V$. vulnificus two different typing methods were used with a total of 97 isolates. Isolates were first ascribed to 16S-type A or B using an RFLP-based analysis. As shown in Table 2, a total of 51 strains were $16 \mathrm{~S}$ type $A$, while 46 were $16 \mathrm{~S}$ type B. Type A strains were predominant before depuration (26 out of 41 ), while $16 S$ type $B$ strains were more abundant after depuration (31 out of 56). However, the increase in the number of $16 \mathrm{~S}$ type $B$ isolates after depuration was not significant.
The high resolution fingerprinting method AFLP confirmed the high intraspecific diversity of this species. AFLP profiles from 70 isolates (DNA quality from the remainder 27 isolates was not sufficient for AFLP typing) showed complex patterns of more than 80 bands comprised in the 50 to $800 \mathrm{bp}$ range. All isolates clustered at $40 \%$ of higher similarity (Figure 4 ) but three distinct clusters could be inferred from the dendrogram. Cluster I groups 15 isolates obtained before depuration with 16 isolates recovered post-depuration. In contrast, cluster II and III grouped for the most part post-depuration isolates ( 27 out of 31 ) and pre-depuration isolates ( 9 out of 10 ), respectively. The results of the AFLP cluster analysis are displayed in Figure 5 using a multidimensional scaling (MDS) plot. In this graph, isolates were ascribed to $16 \mathrm{~S}$ type A and B. Interestingly, AFLP grouping correlated quite well with $16 \mathrm{~S}$ typing. Two main groups could be inferred each one being dominating by one specific $16 \mathrm{~S}$ type.

\section{Discussion}

Depuration is a common practice to eliminate contaminants, mainly of fecal origin, that accumulate in bivalves when they grow in polluted areas. Bivalves can cleanse themselves of fecal contaminants by active feeding if they are placed in tanks with clean water at the right temperature and salinity. However, depuration of naturally occurring bacteria such as $V$. vulnificus presents additional challenges since both bacteria and oysters coexist in the environment and are adapted to each other. Previous studies have evaluated the potential of depuration to eliminate $V$. vulnificus from oysters using recirculating systems $[15-17,23]$ but there has been little investigation into the possibilities of using a flow-through depuration system. Our study was intended to be a 'proof of concept' for using a flow-through depuration system for $V$. vulnificus depuration. Flow-through offers several advantages over re-circulating systems including lower risk of bacteria accumulation in the system (that could serve as reservoir and consequently recolonize the oysters), reduce risk of water quality problems (established biofilters are not required) and no need for artificial feeding since incoming seawater provides enough nutrients for the oysters. Our data showed the ease of eliminating this bacterium from artificially-inoculated oysters using a flowthrough system. Oysters collected during winter months are naturally free of $V$. vulnificus but can quickly uptake $V$. vulnificus cells from water containing the bacterium. However, $V$. vulnificus cells never become established in oyster tissues and are readily cleared $[16,17]$. This is most likely due to the loss of pili or other structures needed for bacterial attachment to oyster tissue by culturing the bacterium under laboratory conditions or that $V$. vulnificus cannot displace the microflora present in the oysters during the winter months. Nevertheless, our first two experiments served to established the basic depuration parameters for our system. The first depuration trial using naturally contaminated oysters (Experiment 3) yielded disappointing results with no significant reduction in $V$. vulnificus numbers in either control or test tanks. Experiment 4 tested depuration at low temperatures as it had been previously suggested that moderate low temperatures do not decrease pumping rate in oysters but negatively affect $V$. vulnificus growth [4]. However, no significant changes in $V$. vulnificus counts pre- and post-depuration were observed when oysters were depurated at $15^{\circ} \mathrm{C}$. Another basic parameter that influences depuration is flow rate. We tested different flow-rates to investigate if a higher water flow will remove feces or pseudo-feces (that may be contaminated with $V$. vulnificus) faster from the system reducing self-contamination risk. Results from depuration trails under higher flow-rates were disparate. While Experiments 5 and 7 did not showed clear differences between 
pre- and post-depuration $V$. vulnificus counts, Experiment 6 results were highly encouraging demonstrating that depuration of naturally occurring $V$. vulnificus is possible in a flow-through system. What made Experiment 6 exceptional was the high salinity encountered during the trial. Vibrio vulnificus numbers in the marine environment are related to water temperature but also to salinity. Environmental data suggest that there is a threshold salinity level (at or slightly above $30 \mathrm{ppt}$ ) at which point $V$. vulnificus levels drop substantially, regardless of temperature [1]. Our results identified to salinity as the main factor influencing depuration of $V$. vulnificus from oysters. Initial V. vulnificus counts were similar in Experiments 4-7 but end point values were dependent on salinity. Experiment 6 (salinity $>30$ ppt) successfully reduced $V$. vulnificus numbers below the FDArequired level while in Experiment 7 (salinity $<10 \mathrm{ppt}$ ) numbers of $V$. vulnificus actually increased during depuration.

The majority of $V$. vulnificus clinical isolates are $16 \mathrm{~S}$ type $\mathrm{B}$ therefore this type has been presumptively correlated with virulence in humans. Analysis of bacterial isolates showed that depuration does not select for specific $V$. vulnificus types but, interestingly, we found a higher percent of $16 \mathrm{~S}$ type $\mathrm{B}(36.5 \%)$ isolates prior to depuration than what has been previously reported [18]. Previous records from this area indicated that only $6 \%$ of total $V$. vulnificus environmental isolates were type B [18]. By contrast, Kim and Jeong [24] found that $65 \%$ of environmental isolates off the southern coast of Korea were 16 S type B [24]. These findings when coupled with the present study indicate geographical location is not the sole determinant of $16 \mathrm{~S}$ type $\mathrm{A} / \mathrm{B}$ ratios in oysters. In fact, it is more likely seasonal, which is illustrated in a study by Lin and Schwarz [25] that showed the prevalence of $16 \mathrm{~S}$ type $\mathrm{B}$ isolates were more prevalent during the summer months which also correlates with the higher incidence of disease. When we analyzed the whole genome of our $V$. vulnificus isolates by AFLP, isolates pre- and post-depuration did not cluster together confirming that depuration is not selecting for specific strains. According to our AFLP data, V. vulnificus is divided into two distinct populations that coexist in oysters and that seem to be equally susceptible to depuration.

In summary, our results suggest that depuration under high salinity conditions has the potential of eliminate $V$. vulnificus from oysters. Motes and DePaola $[26,27]$ have shown that offshore relaying of oysters to high salinity waters ( $>32 \mathrm{ppt}$ ) effectively reduced levels of $V$. vulnificus. Disadvantages of offshore relaying versus an inshore high salinity depuration system include cost of transportation to the offshore site, anchoring permits, and high risk of losing oysters to storms and poachers. On the other hand, maintaining high salinity conditions $(>32 \mathrm{ppt})$ in a flow-through system may not be feasible due to the amount of salt required. Salinity in the coastal areas of the northern Gulf of Mexico can dramatically change overnight making difficult to predict good conditions for inshore depuration. A recirculating system using high salinity could be the best option for future depuration studies and may represent a viable option for the oyster industry to maintain an unprocessed but safe product during the warmer months.

\section{Acknowledgement}

We thank the Alabama Agricultural Experiment Station and Auburn University for funding this project.

\section{References}

1. WHO-FAO (2005) Risk assesment of Vibrio vulnificus in raw oysters. FAO / WHO.

2. Kaysner CA, Abeyta C Jr, Wekell MM, DePaola A Jr, Stott RF, Leitch JM (1987) Virulent strains of Vibrio vulnificus isolated from estuaries of the United States West Coast. Appl Environ Microbiol 53: 1349-51.
3. O'Neil KR, Jones SH, Grimes DJ (1992) Seasonal Incidence of Vibrio vulnificus in the Great bay Estuary of New Hampshire and Maine. Appl Environ Microbiol 58: 3257-62.

4. Cook DW, Bowers JC, DePaola A (2002) Density of total and pathogenic (tdh+) Vibrio parahaemolyticus in Atlantic and Gulf Coast molluscan shellfish at harvesst. J Food Prot 65: 1873-1880.

5. FDACFSAN (2003) Issue relating to Vibrio vulnificus risk management plan for oysters. Interstate Shellfish Sanitation Conference.

6. Jones MK, Oliver JD (2009) Vibrio vulnificus: disease and pathogenesis. Infect Immun 77: 1723-1733.

7. Strom MS, Paranjpye RN (2000) Epidemiology and pathogenesis of Vibrio vulnificus. Microbes Infect 2: 177-188

8. National Marine Fisheries Service. Annual Landings by Species for United States as of 11-May-10.

9. Keithly WR, Diop H (2001) The demand for Eastern oysters, Crassostrea virginica, from the Gulf of Mexico in the presence of Vibrio vulnificus. Marine Fisheries Review 63: 47-53.

10. Wallace RK (2001) Cultivating the Eastern Oyster, Crassostrea virginica. Southern Regional Aquaculture Center 432.

11. Andrews LS, DeBlanc S, Veal CD, Park DL (2003) Response of Vibrio parahaemolyticus $03: \mathrm{K} 6$ to a hot water/cold shock pasteurization process. Food Addit Contam 20: 331-334

12. Lopez-Caballero ME, Perez-Mateos M, Montero P, Borderias AJ (2000) Oyste preservation by high-pressure treatment. Journal of Food Protection 63: 196201

13. Lee R, Lovatelli $A$, and Ababouch $L$ (2008) Bivalve depuration: fundamental and practical aspects. FAO Fisheries Technical Paper 511: 139.

14. Otwell WS, Rodrick GE, Martin RE (1991) Molluscan shellfish depuration. CRC Press, Inc., Boca Raton, FL.

15. Chae MJ, Cheney D, Su YC (2009) Temperature effects on the depuration of Vibrio parahaemolyticus and Vibrio vulnificus from the American oyster (Crassostrea virginica). J Food Sci 74: 62-66.

16. Kelly MT, Dinuzzo A (1985) Uptake and clearance of Vibrio vulnificus from Gulf Coast oysters (Crassostrea virginica). Appl Environ Microbiol 50: 1548-1549.

17. Tamplin ML, Capers GM (1992) Persistance of Vibrio vulnificus in tissues of Gulf Coast oysters, Crassostrea virginica, exposed to seawater deisinfected with UV light. Applied and Environmental Microbiology 58: 1506-1510.

18. Nilsson WB, Pranjype RN, DePaola A, Strom MS (2003) Sequence polymorphism of the 16S rRNA gene of Vibrio vulnificus is a possible indicator of strain virulence. J Clin Microbiol 41: 442-446.

19. Limthammahisorn S, Brady YJ, and Arias CR (2008) Gene expression of cold shock and other stress-related genes in Vibrio vulnificus grown in pure culture under shellstock temperature control conditions. J Food Prot 71: 157-164.

20. FDA (2002) MPN procedure for the enumeration of Vibrio vulnificus using gene probe for identification. FDA/Office of Seafood.

21. Pitcher DG, Saunders NA, Owen RJ (1989) Rapid extraction of bacterial genomic DNA with guanidium thiocyanate. Lett Appl Microbiol 8: 151-156.

22. Panicker G, Bej AK (2005) Real-time PCR detection of Vibrio vulnificus in oysters: comparison of oligonucleotide primers and probes targeting vvhA. Appl Environ Microbiol 71: 5702-5709.

23. Jamison $\mathrm{JL}$ (1992) Laboratory and field evaluations of commercial oyster depuration in the Gulf of Mexico. NOAA.

24. Kim MS, Jeong HD (2001) Development of 16S rRNA targeted PCR methods for the detection and differentiation of Vibrio vulnificus in marine environments. Aquaculture 193: 199-211.

25. Lin M, Schwarz JR (2003) Seasonal shifts in population structure of Vibrio vulnificus in an estuarine environment as revealed by partial $16 \mathrm{~S}$ ribosomal DNA sequencing. FEMS Microbiol Ecol 45: 23-27.

26. Motes ML, DePaola A (1996) Offshore suspension relaying to reduce levels of Vibrio vulnificus in oysters (Crassostrea virginica). Appl Environ Microbiol 62: 3875-3877

27. Rosche TM, Binder EA, Oliver JD (2010) Vibrio vulnificus genome suggests two distinct ecotypes. Environ Microbiol Rep 2: 128-132. 